\title{
Exploring Different Probability Distributions for Rainfall Data of Kodagu - An Assisting Approach for Food Security
}

\author{
R. Shreyas ${ }^{1}$, D. Punith ${ }^{1}$, L. Bhagirathi ${ }^{2}$, Anantha Krishna ${ }^{3}$ and G. M. Devagiri ${ }^{4}$ \\ ${ }^{1}$ UAHS (Shivamogga), College of Forestry, Ponnampet, Karnataka-571216, India \\ ${ }^{2}$ Department of Basic Sciences, College of Forestry, Ponnampet, Karnataka-571216, India \\ ${ }^{3}$ Department of Computer Science, College of Forestry, Ponnampet, Karnataka-571216, India \\ ${ }^{4}$ Department of Natural Resource Management, College of Forestry, Ponnampet,
}

Karnataka-571216, India

*Corresponding author

\section{Keywords}

Rainfall, probability distributions, fitting, goodness-of-fit

Article Info

Accepted:

20 January 2020

Available Online:

10 February 2020

\section{A B S T R A C T}

Rainfall intensity, duration and its distribution play a major role in the growth of agriculture and other related sectors and the overall development of a country. The present study is carried out to know the best fitting probability distribution for rainfall data in three different taluks of Kodagu District. The time series data of average monthly and annual rainfall over a period of 61 years (1958-2018) was collected from KSNDMC, Bangalore. Around 26 different probability distributions were used to evaluate the best fit for annual and seasonal rainfall data. Kolmogorov-Smirnov, Anderson Darling and Chi-squared tests were used for the goodness of fit test. The best fitting distribution was identified by maximum score which is a sum of ranks given by three selected goodness of fit test for the distributions which is again based on fitting distance. Among various distributions attemptedLog Logistic (3P), Dagum, Gamma (3P), Inverse Gaussian, Generalized Gamma, Pearson Type 5 (3P) and Pearson 6 were found to be the best fit for annual and seasonal rainfall for different taluks of Kodagu district.

\section{Introduction}

Indian agriculture sector accounts for around 14 percent of the country's economy but accounts for 42 percent of total employment in the country. About 55 percent of India's arable land depends on precipitation, the amount of rainfall during the monsoon season is very important for economic activity.

Rainfall intensity, duration and its distribution play a major role in the growth of agriculture and other related sectors and the overall development of a country. Rainfall intensity, 
patterns and its distribution are altered by natural climatic variability i.e., decadal changes in circulation (Deepthi K.A, 2015) as well as human induced changes i.e., land use and cover, emission of greenhouse gases, etc. The variability in rainfall affects the agricultural production, water supply, transportation, the entire economy of a region, and the existence of its people. In regions where the year-to-year variability is high, people often suffer great calamities due to floods or droughts. The damage due to extremes of rainfall cannot be avoided completely, a forewarning could certainly be useful and it's possible from analysis of rainfall data.

In India, the monsoon or rainy season is dominated by the humid South West Monsoon that sweeps across the country in early June, first hitting the State of Kerala. The southwest monsoon is generally expected to begin in early June and end by September and the total rainfall of these four months is considered as monsoon rainfall. In Indian agriculture, the contribution of south-west monsoon is immense as more than $70 \%$ of India's annual rainfall is from the south west monsoon and supports nearly $75 \%$ of the kharif crop which is critical to India's food security.

The prediction of rainfall at a particular place and time can be made by studying the behavior of rainfall of that place over several years during the past. This behavior is best studied by fitting a suitable distribution to the time series data on the rainfall (Kainth 1996). The rainfall is predicted with the help of the probability estimates. Probability and frequency analysis of rainfall data enables to determine the expected rainfall at different probability level (Mishra et al., 2013).

The probability distributions are used in different fields of science such as engineering, medicine, climatology, economics and agricultural science. Probability distributions of rainfall have been studied by many researchers.

The main objective of this study is to identify a suitable probability distribution for annual and seasonal rainfall in the different taluks of Kodagu.

\section{Materials and Methods}

Kodagu district with an area of $4102 \mathrm{~km} \mathrm{sq}$. is one of the smallest districts in the state of Karnataka, located between $11^{0} 56^{\prime} 00^{\prime \prime}$ and $12^{\circ} 50$ '00' North latitude and between $75^{\circ} 22^{\prime} 00^{\prime \prime}$ and $76^{\circ} 11^{\prime} 00^{\prime \prime}$ East longitude. The average annual rainfall is around $2682 \mathrm{~mm}$ (Anonymous, 2018). The District is composed of three taluks namely Madikeri, Somwarpet and Virajpet.

\section{Data}

Rainfall of three taluks of Kodagu district was selected with annual and seasonal series from 1958 to 2018. The required rainfall data for the study was collected from Karnataka State Natural Disaster Monitoring Centre (KSNDMC) situated at Bangalore.

\section{Methodology}

The procedures adopted for this work can be summarized in the following steps:

\section{Statistics of annual and seasonal period rainfall}

Using the sample data $(\mathrm{i}=1,2 \ldots, \mathrm{n})$ the basic statistical descriptors of the annual rainfall series, the mean, standard deviation, coefficient of variation (CV), skewness, kurtosis, minimum and maximum values, have been estimated for each taluk of Kodagu district. 


\section{Distribution Fitting}

The annual average and seasonal period rainfall data for each of the 3 taluk of Kodagu district are fitted to the selected 26 continuous probability distributions as presented in table 1 .

Testing the goodness of fit

The goodness-of-fit tests namely, Kolmogorov Smirnov test, Anderson-Darling test and Chi-Squared test were used at $\alpha$
(0.05) level of significance for the selection of the best fit distribution. The hypothesis under the GOF test is:

$\mathrm{H}_{0}$ : MMR data follow the specified distribution,

$\mathrm{H}_{1}$ : MMR data does not follow the specified distribution.

The best fitted distribution is selected based on the minimum error produced, which is evaluated by the following techniques:

Table.1 Description for continuous probability distribution

\begin{tabular}{|c|c|c|c|c|}
\hline $\begin{array}{l}\text { Sl } \\
\text { No }\end{array}$ & $\begin{array}{c}\text { Distributio } \\
\mathbf{n}\end{array}$ & Probability Distribution Function $\mathbf{f}(\mathbf{x})$ & Range/values & Parameters \\
\hline 1 & Burr (3P) & $f(x)=\frac{a k\left(\frac{x}{\beta}\right)^{\alpha-1}}{\beta\left(1+\left(\frac{x}{\beta}\right)^{\alpha}\right)^{\kappa+1}}$ & $\begin{array}{l}\kappa, \alpha, \beta>0 \\
0 \leq x<+\infty\end{array}$ & $\begin{array}{l}\kappa, a=\text { shape } \\
\beta=\text { scale }\end{array}$ \\
\hline 2 & Burr (4P) & $f(x)=\frac{a k\left(\frac{x-\gamma}{\beta}\right)^{\alpha \kappa-1}}{\beta\left(1+\left(\frac{x-y}{\beta}\right)^{\alpha}\right)^{\kappa+1}}$ & $\begin{array}{l}\kappa, \alpha, \beta>0 \\
\gamma \leq x<+\infty\end{array}$ & $\begin{array}{l}\kappa, a=\text { shape } \\
\beta=\text { scale } \\
\gamma=\text { location }\end{array}$ \\
\hline 3 & $\begin{array}{l}\text { Dagum } \\
(3 \mathrm{P})\end{array}$ & $\frac{a k\left(\frac{x}{\beta}\right)^{\alpha \kappa-1}}{\beta\left(1+\left(\frac{x}{\beta}\right)^{\alpha}\right)^{\kappa+1}}$ & $\begin{array}{l}\kappa, \alpha, \beta>0 \\
0 \leq x<+\infty\end{array}$ & $\begin{array}{l}\kappa, a=\text { shape } \\
\beta=\text { scale }\end{array}$ \\
\hline 4 & $\begin{array}{l}\text { Dagum } \\
(4 \mathrm{P})\end{array}$ & $\frac{a k\left(\frac{x-\gamma}{\beta}\right)^{\alpha \kappa-1}}{\beta\left(1+\left(\frac{x-y}{\beta}\right)^{\alpha}\right)^{\kappa+1}}$ & $\begin{array}{l}\kappa, \alpha, \beta>0 \\
\gamma \leq x<+\infty\end{array}$ & $\begin{array}{l}\kappa, a=\text { shape } \\
\beta=\text { scale } \\
\gamma=\text { location }\end{array}$ \\
\hline 5 & $\begin{array}{c}\text { Fatigue } \\
\text { Life }\end{array}$ & $\frac{\sqrt{x / \beta}+\sqrt{\beta / x}}{2 \alpha(x-y)} \cdot \phi\left(\frac{1}{\alpha}\left(\sqrt{\frac{x}{\beta}}-\sqrt{\frac{\beta}{x}}\right)\right)$ & $\begin{array}{l}\alpha, \beta,>0 \\
0<x<+\infty\end{array}$ & $\begin{array}{l}a=\text { shape } \\
\beta=\text { scale }\end{array}$ \\
\hline
\end{tabular}




\begin{tabular}{|c|c|c|c|c|}
\hline 6 & $\begin{array}{c}\text { Fatigue } \\
\text { Life (3P) }\end{array}$ & $\frac{\sqrt{(x-\gamma) / \beta}+\sqrt{\beta /(x-\gamma)}}{2 \alpha(x-y)} \cdot \phi\left(\frac{1}{\alpha}\left(\sqrt{\frac{x-\gamma}{\beta}}-\sqrt{\frac{\beta}{x-\gamma}}\right)\right)$ & $\begin{array}{l}\alpha, \beta,>0 \\
\gamma<x<+\infty\end{array}$ & $\begin{array}{l}a=\text { shape } \\
\beta=\text { scale } \\
\gamma=\text { location }\end{array}$ \\
\hline 7 & $\begin{array}{l}\text { Gamma } \\
\text { (2P) }\end{array}$ & $f(x)=\frac{(x)^{\alpha-1}}{\beta^{\alpha} \Gamma(\alpha)} \exp (-x / \beta)$ & $\begin{array}{l}\alpha, \beta,>0 \\
0 \leq x<+\infty\end{array}$ & $\begin{array}{l}a=\text { shape } \\
\beta=\text { scale }\end{array}$ \\
\hline 8 & $\begin{array}{l}\text { Gamma } \\
(3 \mathrm{P})\end{array}$ & $f(x)=\frac{(x-\gamma)^{\alpha-1}}{\beta^{\alpha} \Gamma(\alpha)} \exp (-(x-\gamma) / \beta)$ & $\begin{array}{l}\alpha, \beta,>0 \\
\gamma \leq x<+\infty\end{array}$ & $\begin{array}{l}a=\text { shape } \\
\beta=\text { scale } \\
\gamma=\text { location }\end{array}$ \\
\hline 9 & $\begin{array}{l}\text { Gen. } \\
\text { Extreme } \\
\text { Value }\end{array}$ & $f(x)= \begin{cases}\frac{1}{\sigma} \exp \left(-(1-\kappa z)^{\frac{-1}{\kappa}}\right)(1+\kappa z)^{-1-1 / \kappa} & \kappa \neq 0 \\
\frac{1}{\sigma} \exp (-z-\exp (-z)) & \kappa=0\end{cases}$ & $\begin{array}{l}\alpha, \beta,>0 \\
\gamma \leq x<+\infty\end{array}$ & $\begin{array}{l}a=\text { shape } \\
\beta=\text { scale } \\
\gamma=\text { location }\end{array}$ \\
\hline 10 & $\begin{array}{c}\text { Gen. } \\
\text { Gamma }\end{array}$ & $\frac{k x^{k \alpha-1}}{\beta^{k \alpha} \Gamma(\alpha)} \exp \left(-(x / \beta)^{k}\right)$ & $\begin{array}{l}\kappa, \alpha, \beta>0 \\
0 \leq x<+\infty\end{array}$ & $\begin{array}{l}k, a=\text { shape } \\
\beta=\text { scale }\end{array}$ \\
\hline 11 & $\begin{array}{l}\text { Gen. } \\
\text { Gamma } \\
(4 \mathrm{P})\end{array}$ & $f(x)=\frac{k(x-\gamma)^{k \alpha-1}}{\beta^{k \alpha} \Gamma(\alpha)} \exp \left(-((x-\gamma) / \beta)^{k}\right)$ & $\begin{array}{l}\kappa, \alpha, \beta>0 \\
\gamma \leq x<+\infty\end{array}$ & $\begin{array}{l}\kappa, a=\text { shape } \\
\beta=\text { scale } \\
\gamma=\text { location }\end{array}$ \\
\hline 12 & $\begin{array}{c}\text { Gumbel } \\
\text { Max }\end{array}$ & $\begin{array}{c}f(x)=\frac{1}{\sigma} \exp (-z-\exp (-z)) \\
\text { Where, } \\
f(x)=\frac{x-\mu}{\sigma}\end{array}$ & $-\infty<x<+\infty$ & $\begin{array}{l}\sigma=\text { scale } \\
\mu=\text { location }\end{array}$ \\
\hline 13 & $\begin{array}{c}\text { Inv. } \\
\text { Gaussian }\end{array}$ & $\sqrt{\frac{\lambda}{2 \pi x^{3}}} \exp \left[-\frac{\lambda(x-\mu)^{2}}{2 \mu^{2} x}\right]$ & $\begin{array}{l}\lambda, \mu>0 \\
0<x<+\infty\end{array}$ & $\begin{array}{l}\lambda=\text { shape } \\
\mu=\text { location }\end{array}$ \\
\hline 14 & $\begin{array}{l}\text { Inv. } \\
\text { Gaussian } \\
(3 \mathrm{P})\end{array}$ & $\sqrt{\frac{\lambda}{2 \pi(x-\gamma)^{3}}} \exp \left[-\frac{\lambda(x-\gamma-\mu)^{2}}{2 \mu^{2}(x-\gamma)}\right]$ & $\begin{array}{l}\lambda, \mu>0 \\
\gamma<x<+\infty\end{array}$ & $\begin{array}{l}\lambda=\text { shape } \\
\gamma, \mu=\text { location }\end{array}$ \\
\hline 15 & $\begin{array}{c}\text { Johnson } \\
\text { SB }\end{array}$ & $f(x)=\frac{\delta}{\lambda \sqrt{2 \pi} z(1-z)} \exp \left(-\frac{1}{2}\left(\gamma+\delta \ln \left(\frac{z}{1-z}\right)\right)^{2}\right)$ & $\zeta \leq x \leq \zeta+\lambda$ & $\begin{array}{l}\delta, \gamma=\text { shape } \\
\lambda=\text { scale } \\
\zeta=\text { location }\end{array}$ \\
\hline 16 & $\begin{array}{c}\text { Log- } \\
\text { Logistic }\end{array}$ & $\frac{\alpha}{\beta}\left[\frac{x}{\beta}\right]^{\alpha-1}\left[1+\left[\frac{x}{\beta}\right]^{\alpha}\right]^{-2}$ & $\begin{array}{l}\alpha, \beta,>0 \\
0 \leq x<+\infty\end{array}$ & $\begin{array}{l}a=\text { shape } \\
\beta=\text { scale }\end{array}$ \\
\hline
\end{tabular}




\begin{tabular}{|c|c|c|c|c|}
\hline 17 & $\begin{array}{l}\text { Log- } \\
\text { Logistic } \\
\text { (3P) }\end{array}$ & $\frac{\alpha}{\beta}\left[\frac{x-\gamma}{\beta}\right]^{\alpha-1}\left[1+\left[\frac{x-\gamma}{\beta}\right]^{\alpha}\right]^{-2}$ & $\begin{array}{l}\alpha, \beta,>0 \\
\gamma \leq x<+\infty\end{array}$ & $\begin{array}{l}a=\text { shape } \\
\beta=\text { scale } \\
\gamma=\text { location }\end{array}$ \\
\hline 18 & $\begin{array}{c}\text { Log- } \\
\text { Pearson } 3\end{array}$ & $f(x)=\frac{1}{X|\beta| \Gamma(\alpha)}\left(\frac{\ln (X)-\gamma}{\beta}\right)^{\alpha-1} \exp \left(-\frac{\ln (X)-\gamma}{\beta}\right)$ & $\begin{array}{c}\alpha>0 \\
\beta \neq 0 \\
\begin{cases}0<x \leq e^{y} & \beta<0 \\
e^{y} \leq x<+\infty & \beta>0\end{cases} \end{array}$ & $\begin{array}{l}a=\text { shape } \\
\beta=\text { scale } \\
\gamma=\text { location }\end{array}$ \\
\hline 19 & $\begin{array}{c}\text { Log- } \\
\text { Normal }\end{array}$ & $\frac{\exp \left[-\frac{1}{2}\left[\frac{\ln (x-\mu}{\sigma}\right]^{2}\right]}{x \sigma \sqrt{2 \pi}}$ & $\begin{array}{l}\sigma>0 \\
-\infty<\mu<\infty \\
0<x<+\infty\end{array}$ & $\begin{array}{l}\sigma=\text { shape } \\
\mu=\text { scale }\end{array}$ \\
\hline 20 & $\begin{array}{l}\text { Log- } \\
\text { Normal } \\
(3 \mathrm{P})\end{array}$ & $\frac{\exp \left[-\frac{1}{2}\left[\frac{\ln (x-\gamma)-\mu}{\sigma}\right]^{2}\right]}{(x-\gamma) \sigma \sqrt{2 \pi}}$ & $\begin{array}{l}\sigma>0 \\
-\infty<\mu<\infty \\
\gamma<x<+\infty\end{array}$ & $\begin{array}{l}\sigma=\text { shape } \\
\mu=\text { scale } \\
\lambda=\text { location }\end{array}$ \\
\hline 21 & Pearson 5 & $\frac{\exp (-\beta / x)}{\beta \Gamma(\alpha)(x / \beta)^{\alpha+1}}$ & $\begin{array}{l}\alpha, \beta,>0 \\
0<x<+\infty\end{array}$ & $\begin{array}{l}a=\text { shape } \\
\beta=\text { scale }\end{array}$ \\
\hline 22 & $\begin{array}{c}\text { Pearson } 5 \\
\text { (3P) }\end{array}$ & $\frac{\exp (-\beta /(x-\gamma))}{\beta \Gamma(\alpha)((x-\gamma) / \beta)^{\alpha+1}}$ & $\begin{array}{l}\alpha, \beta,>0 \\
\gamma<x<+\infty\end{array}$ & $\begin{array}{l}a=\text { shape } \\
\beta=\text { scale } \\
\gamma=\text { location }\end{array}$ \\
\hline 23 & Pearson 6 & $f(x)=\frac{(x / \beta)^{\alpha_{1}-1}}{\beta B\left(\alpha_{1}, \alpha_{2}\right)(1+x / \beta)^{\alpha_{1}+\alpha_{2}}}$ & $\begin{array}{l}\alpha_{1}, \alpha_{2}, \beta>0 \\
0 \leq x<+\infty\end{array}$ & $\begin{array}{l}\alpha_{1}, \alpha_{2}=\text { shape } \\
\beta=\text { scale }\end{array}$ \\
\hline 24 & $\begin{array}{c}\text { Pearson } 6 \\
\text { (4P) }\end{array}$ & $f(x)=\frac{((x-\gamma) / \beta)^{\alpha_{1}-1}}{\beta B\left(\alpha_{1}, \alpha_{2}\right)(1+(x-\gamma) / \beta)^{\alpha_{1}+\alpha_{2}}}$ & $\begin{array}{l}\alpha_{1}, \alpha_{2}, \beta>0 \\
\gamma \leq x<+\infty\end{array}$ & $\begin{array}{l}\alpha_{1}, \alpha_{2}=\text { shape } \\
\beta=\text { scale } \\
\gamma=\text { location }\end{array}$ \\
\hline 25 & Weibull & $f(x)=\frac{\alpha}{\beta}\left(\frac{x}{\beta}\right)^{\alpha-1} \exp \left(-\left(\frac{x}{\beta}\right)^{\alpha}\right)$ & $\begin{array}{l}\alpha, \beta,>0 \\
0 \leq x<+\infty\end{array}$ & $\begin{array}{l}a=\text { shape } \\
\beta=\text { scale }\end{array}$ \\
\hline 26 & $\begin{array}{l}\text { Weibull } \\
\text { (3P) }\end{array}$ & $f(x)=\frac{\alpha}{\beta}\left(\frac{x-\gamma}{\beta}\right)^{\alpha-1} \exp \left(-\left(\frac{x-\gamma}{\beta}\right)^{\alpha}\right)$ & $\begin{array}{l}\alpha, \beta,>0 \\
\gamma \leq x<+\infty\end{array}$ & $\begin{array}{l}a=\text { shape } \\
\beta=\text { scale } \\
\gamma=\text { location }\end{array}$ \\
\hline
\end{tabular}




\section{Kolmogorov-Smirnov test}

Is used to decide if a sample $\left(\mathrm{x}_{1}, \mathrm{x}_{2}, \mathrm{x}_{\mathrm{n}}\right)$ with CDF $\mathrm{F}(\mathrm{x})$ comes from a hypothesized continuous distribution. The KolmogorovSmirnov statistic (D) is based on the largest vertical difference between the theoretical $\mathrm{CDF}$ and the empirical (observed) CDF and is given by

$$
D=\max _{1<i<n}\left[F\left(x_{i}\right)-\frac{i-1}{n}, \frac{i}{n}-F\left(x_{i}\right)\right]
$$

A large difference indicates an inconsistency between the observed data and the statistical model.

\section{Results and Discussion}

\section{Anderson-Darling Test}

The Anderson-Darling test it was introduced by Anderson and Darling (1952) to place more weight or discriminating power at the tails of the distribution. This can be important when the tails of the selected theoretical distribution are of practical significance.

It is used to compare the fit of an observed $\mathrm{CDF}$ to an expected CDF. This test gives more weight to the tails than the Kolmogorov -Smirnov test. The test statistic (A2), is defined as

$$
A^{2}=-n-\frac{1}{n} \sum_{i=1}^{n}(2 i-1)\left[\ln F\left(x_{i}\right)+\ln \left(1-F\left(x_{n-i+1}\right)\right)\right]
$$

\section{Chi-Squared Test}

The Chi-Squared test is used to determine if a sample comes from a population with a specific distribution. The Chi-Squared statistic is defined as

$$
\chi^{2}=\sum_{i=1}^{n} \frac{\left(O_{i}-E_{i}\right)^{2}}{E_{i}}
$$

Where $O_{i}$ is the observed frequency for bin $i$ and $E_{i}$ is the expected (theoretical) $x^{2}$ frequency for bin $I$ calculated by $E_{\mathrm{i}}=F\left(\mathrm{X}_{2}\right)$ $F\left(\mathrm{X}_{1}\right), F$ is the CDF of the probability distribution being tested, $X_{1}$ and $X_{2}$ limits for bin $i$.

Based on Kolmogorov-Smirnov, AndersonDarling and Chi-squared GOF test statistic values, 3 different rankings have been given to each of the distributions for all the taluk. No rank is given to a distribution when the concerned test fails to fit the data. Results of the GOF tests for all the districts are depicted in Table 3 to 4.

\section{Identification of best fitted probability distribution}

The three goodness of fit test mentioned above were fitted to the maximum rainfall data treating different data set. The test statistic of each test was computed and tested at $(\mathrm{a}=0.05)$ level of significance.

Accordingly, the ranking of different probability distributions was marked from 1 to 26 based on minimum test statistic value. The distribution holding the first rank was selected for all the three tests independently. The assessments of all the probability distribution were made on the bases of total test score obtained by combining the entire three tests.

Maximum score 26 was awarded to rank first probability distribution to the data based on the test statistic and further less score was awarded to the distribution having rank more than 1, that is 2 to 26 and in some case where the distribution was not fit it was scored 0 . Thus, the total score of the entire three tests were summarized to identify the best fit distribution on the bases of highest score obtained (Sharma, 2010). 


\section{Descriptive statistics}

Mean, Minimum, Maximum, Range, Standard deviation (SD), coefficient of variance, skewness and Kurtosis are the descriptive statistics for annual and seasonal period rainfall of three taluk that are summarized in table 2 and 3.

Over a span of 61 years among the three taluks of Kodagu district, Virajpet taluk showed the highest range value of rainfall. Madikeri taluk received a highest mean of $3293.094 \mathrm{~mm}$ while Somwarpet taluk received a lowest mean of $2154.980 \mathrm{~mm}$.

High SD (713.174 $\mathrm{mm})$ is observed for Madikeri taluk imply that there is large variation in average annual rainfall while less variation is observed for Somwarpet taluk with less SD (523.763 mm).

$\mathrm{CV}$ indicates the irregularities in the average annual rainfall. Among the three taluks, Madikeri with less CV (21.70\%) showed more consistence while Virajpet with high CV (25.20\%) showed relatively inconsistent. Skewness measures the asymmetry of a distribution around the mean. For all taluks the skewness is positively skewed indicating that average annual rainfall is positively skewed.
The value of kurtosis ranges from -0.708 to 4.972. Virajpet taluk has the highest value of kurtosis implying the possibility of a distribution having a distinct peak near to the mean with a heavy tail.

Somwarpet taluk has the smallest negative value of kurtosis which indicates that the distribution is probably characterized with a relatively flat peak near to the mean and which is too flat to be normal.

From table 3, we can say that Virajpet taluk showed the highest range value of rainfall. Highest mean of $2771.874 \mathrm{~mm}$ is observed during the S-W monsoon period of Madikeri taluk and the lowest mean of $208.606 \mathrm{~mm}$ for Somwarpet during Pre-monsoon period. High SD of $670.568 \mathrm{~mm}$ is shown during S-W monsoon of Madikeri taluk imply that there is large variation in average annual rainfall while less variation is observed during premonsoon period of Somwarpet taluk with SD of $100.761 \mathrm{~mm}$.

Pre-monsoon period of Madikeri with less CV of $24.2 \%$ showed more consistence while pre-monsoon period of Virajpet with high CV of 0.523 shows inconsistency in relative terms. For all taluks the skewness is positive. The value of kurtosis ranges from -0.313 for S-W of Somwarpet to 3.136 for Postmonsoon of Virajpet.

Table.2 Descriptive statistics of annual average period for three taluks of Kodagu

\begin{tabular}{|c|c|c|c|c|c|c|c|c|}
\hline Taluk Name & Min & Max & Range & Mean & SD & CV (\%) & Skewness & Kurtosis \\
\hline Madikeri & 1929.800 & 5829.200 & 3899.400 & 3293.094 & 713.174 & 21.70 & 0.854 & 1.832 \\
\hline Somwarpet & 1290.400 & 3215.200 & 1924.800 & 2154.980 & 523.763 & 24.30 & 0.249 & -0.708 \\
\hline Virajpet & 1251.200 & 5175.300 & 3924.040 & 2455.737 & 617.761 & 25.20 & 1.504 & 4.972 \\
\hline
\end{tabular}


Int.J.Curr.Microbiol.App.Sci (2020) 9(2): 2972-2980

Table.3 Descriptive statistics of monsoon period for three taluks of Kodagu

\begin{tabular}{|r|c|c|c|c|c|c|c|c|c|}
\hline Taluk & $\begin{array}{c}\text { Monsoon } \\
\text { Season }\end{array}$ & Min & Max & Range & Mean & SD & CV (\%) & Skewness & Kurtosis \\
\hline \multirow{2}{*}{ Madikeri } & Pre & 62.600 & 623.300 & 560.700 & 244.939 & 126.373 & 51.60 & 1.299 & 2.102 \\
\cline { 2 - 10 } & S-W & 1462.900 & 4888.800 & 3425.900 & 2771.874 & 670.568 & 24.20 & 0.797 & 0.911 \\
\cline { 2 - 11 } & Post & 94.400 & 618.000 & 523.600 & 276.281 & 116.374 & 42.10 & 0.912 & 0.612 \\
\hline \multirow{2}{*}{ Somwarpet } & Pre & 86.00 & 589.90 & 503.90 & 208.606 & 100.761 & 48.30 & 1.360 & 2.342 \\
\cline { 2 - 11 } & S-W & 875.90 & 2907.30 & 2031.40 & 1710.932 & 473.392 & 27.70 & 0.497 & -0.313 \\
\cline { 2 - 11 } & Post & 37.50 & 559.40 & 521.90 & 235.441 & 105.570 & 44.80 & 0.570 & 0.424 \\
\hline \multirow{2}{*}{ Virajpet } & Pre & 66.50 & 691.80 & 625.30 & 252.783 & 132.081 & 52.30 & 1.401 & 2.148 \\
\hline & S-W & 1037.97 & 4247.90 & 3209.93 & 1936.535 & 578.085 & 29.90 & 1.308 & 3.136 \\
\hline & Post & 72.00 & 614.80 & 542.80 & 266.420 & 124.931 & 46.90 & 0.905 & 0.717 \\
\hline
\end{tabular}

Table.4 Score wise best fitted probability distribution with parameter estimates for average annual rainfall of three taluks of Kodagu district

\begin{tabular}{|c|c|c|c|c|}
\hline SLNo. & Taluk & Name of Distribution & Total Score & Distribution Parameter Estimates \\
\hline 1 & Madikeri & Log Logistic (3P) & 75 & $\begin{array}{c}\alpha=8.486, \beta=3195.000 \\
\gamma=28.949\end{array}$ \\
\hline 2 & Somwarpet & Log Logistic & 77 & $\alpha=6.728, \beta=2076.700$ \\
\hline 3 & Virajpet & Gumbel Max & 71 & $\sigma=481.600, \mu=2177.700$ \\
\hline
\end{tabular}

Table.5 Score wise best fitted probability distribution with parameter estimates for rainfall of monsoon period of three taluks of Kodagu district

\begin{tabular}{|c|c|c|c|c|}
\hline Taluk & Season & Name of Distribution & $\begin{array}{l}\text { Total } \\
\text { Score }\end{array}$ & Distribution Parameter Estimates \\
\hline \multirow[t]{3}{*}{ Madikeri } & Pre monsoon & Dagum & 78 & $\kappa=0.662, \alpha=4.150, \beta=259.020$ \\
\hline & $\begin{array}{l}\text { South-west } \\
\text { monsoon }\end{array}$ & Log Logistic (3P) & 78 & $\alpha=6.561, \beta=2322.200, \gamma=362.720$ \\
\hline & Post monsoon & Log Logistic (3P) & 75 & $\alpha=4.408 \beta=266.140 \gamma=-10.466$ \\
\hline \multirow[t]{3}{*}{ Somwarpet } & Pre monsoon & Inv. Gaussian & 72 & $\lambda=894.130, \mu=208.610$ \\
\hline & $\begin{array}{l}\text { South-west } \\
\text { monsoon }\end{array}$ & Gen Gamma & 72 & $\kappa=1.006, \alpha=13.272, \beta=130.980$ \\
\hline & Post monsoon & Gamma (3P) & 70 & $\alpha=9.704, \beta=33.796, \gamma=-92.498$ \\
\hline \multirow[t]{3}{*}{ Virajpet } & Pre monsoon & Pearson 6 & 59 & $\alpha_{1}=13.634, \alpha_{2}=6.454, \beta=101.440$ \\
\hline & $\begin{array}{c}\text { South-west } \\
\text { monsoon }\end{array}$ & Pearson $5(3 \mathrm{P})$ & 66 & $\alpha=13.609, \beta=24600.000, \gamma=-14.481$ \\
\hline & Post monsoon & Log-Logistic (3P) & 78 & $\alpha=4.533, \beta=297.110, \gamma=-51.978$ \\
\hline
\end{tabular}


It is observed from table 4 that Log-Logistic 3P distribution comes best fit for Madikeri taluk while Log-Logistic and Gumbel max distribution are found to be more suitable for Somwarpet and Virajpet taluk respectively. In table 5 it is observed that Log-logistic (3P) is found to be most fitted distribution for S-W monsoon period of Madikeri, post monsoon period of Madikeri and Virajpet taluks respectively.

While Dagum, Inv. Gaussian, Gen. Gamma, Gamma, Pearson 6 and Pearson 5 (3P) distributions were found to be most suitable for Pre-monsoon period (Madikeri), Premonsoon period (Somwarpet), S-W monsoon period (Somwarpet), Post-monsoon period (Somwarpet), Pre-monsoon period (Virajpet) and S-W monsoon period (Virajpet) respectively.

\section{References}

Anonymous. 2018.Annual and Seasonal Rainfall Pattern and Area Coverage during Kharif and Rabi seasons of 2017, Directorate of Economics and statistics, special report No. DES/ $10 / 2018$.

Bhavyashree, S. and Bhattacharyya, B. 2018. Fitting Probability Distribution for rainfall Analysis of Karnataka, India. Int. J. Curr. Microbiol. and App. Sci., 7(3):2319-7706.

Deepthi, K.A. 2015. Analysis of Temporal and Spatial rainfall of Kodagu District. Ms.c. thesis, Univ. Agri. Sci.,
Bangalore, Karnataka (India). p 1-4,21. Ghosh, S., Roy, M. K. and Biswas, S.C. 2016. Determination of the best fit Probability Distribution for Monthly Rainfall Data in Bangladesh. American J. of Mathematics and Statistics., 66(4):170174.

Kainth, G. S. 1996. Weather and Supply Behaviour in Agriculture: An Econometric Approach. Daya Books.

Mandal, K.G., Padhi, J., Kumar, A., Ghosh, S., Panda, D.K., Mohanty, R.K., Raychaudhuri, M. 2014.Analyses of rainfall using probability distribution and Markovchain models for crop planning in Daspalla region in Odisha, India. J. Theor Appl. Climatol.,121(34):517-528.

Mishra, P. K., Khare, D., Mondal, A., Kundu, S. and Shukla, R. 2013."Statistical and Probability Analysis of Rainfall for Crop Planning in A Canal Command". Agriculture for Sustainable Development, 1(1):45-52.

Sukrutha, A., Dyuthi, S.R. And Desai, S. 2018. Multimodel response assessment for monthly rainfall distribution in some selected cities using best-fit probability as a tool. Open access J. Applied water Sci., 8(5):145

Yue, S., and Hashino, M. 2007. Probability distribution of annual, seasonal and monthly precipitation in Japan. Hydrological sci. J. des. Sci. Hydrologiques., 52(5):863-877.

\section{How to cite this article:}

Shreyas. R, D. Punith, L. Bhagirathi, Anantha Krishna and Devagiri. G. M. 2020. Exploring Different Probability Distributions for Rainfall Data of Kodagu - An Assisting Approach for Food Security. Int.J.Curr.Microbiol.App.Sci. 9(02): 2972-2980.

doi: https://doi.org/10.20546/ijcmas.2020.902.339 